\title{
In Memoriam: My Unforgettable Journey with Eli E. Sercarz
}

My first encounter with Eli Sercarz was at the University of California-Los Angeles (UCLA) as a senior undergraduate, a new emigrant from Paris, where I had been in medical school and changed course in the United States. Before Eli's arrival, immunology at UCLA was taught primarily on general serology and very little on the fundamental principles of the immune system as was known at that time. I was lucky to attend Eli's class after having attended the old course. I was overwhelmed by the new immunology that Eli taught with such enthusiasm and compassion. I was attracted by his lectures and fell "in love" with the subject. It was then that I decided to leave medical school and pursue a career in immunology. I was lucky that Eli accepted me as a volunteer in his laboratory until my graduation.

He then accepted me as a doctoral student and introduced me to the field of immunochemistry of a well-characterized protein, hen egg-white lysozyme (HEL). My thesis project was to map immunogenic, antigenic, and tolerogenic epitopes of HEL, a subject that he had initiated shortly before and which became his long-term research subject as applied to immune diseases. This subject was poorly investigated by others and enabled me to develop the skills and methodologies, with his guidance, to systematically analyze and characterize various epitopes on HEL using various approaches. These methodologies consisted of biochemical and physical analyses, immune analyses, and laboratory and animal studies, but most of all I learned how to test hypotheses and defend them. The art of writing scientific manuscripts and presentations at conferences were novel to me, but I was able to work on learning these skills as well.

My time in Eli's laboratory was filled with many lovely interactions with him both one-on-one and as part of the larger laboratory group. His laboratory was growing steadily, with new students and fellows arriving and a large flow of visitors, so Eli was always very busy writing manuscripts and grants to support his group. Because he was so busy, he was not always available to attend to everyone in his group. I was a novice, naïve and unexperienced, and I depended on his attention. He always made time for me. He was usually late for his appointments, but always responsive. He always supported his students by introducing them to visitors and helping them to submit abstracts to the American Association of Immunology to present their research. Those were stressful times because the abstracts were always sent at the last minute after undergoing many changes. The preparations of the slides for the conference presentations were usually completed late at night the day before the travel. However, the presentations were always successful and rewarding for students.

During my tenure, I also was involved in a different research project that deals with the immunology of tears and tear lysozyme. This involvement was the result of an ophthalmologist, Dr. A. Sapse, who joined Eli's laboratory because he was interested in learning immunology. This association was very beneficial and expanded my research abilities and writing skills.

Eli was young in spirit and down to earth. I felt at ease with him and considered him as not just a friend, but as a family member. Dr. M. Sela from the Weizmann Institute at Rehovot, Israel, an international scientist in the field of immunochemistry using synthetic polypeptides/peptides to define the antigenicity and tolerogenicity of amino acid sequences, a similar approach used by Eli with biological proteins, was invited by Eli to UCLA. I was interested in doing my postdoctoral fellowship in Israel, and Dr. Sela was my preferred choice. Eli recommended me, and I was awarded a two-year Weizmann Fellowship. At the Institute, I was involved with the immunochemistry of nucleic acids (DNA, RNA, tRNA) and learned and published a great deal. Before the end of my two years, I received a call from Dr. J. Fahey, newly recruited to Chair the Department of Microbiology and Immunology at the UCLA School of Medicine, for an 
interview in Washington, DC, during the AAI conference. I was surprised by this unanticipated call because I was contemplating my stay at Weizmann and had been planning to stay longer. A short time after my interview, I received a letter from Dr. Fahey offering me an academic position in his department at UCLA. I accepted the position and returned back to UCLA in an office not too far from Eli's in the Department Microbiology, College of Letters and Science. I was very glad to be close to Eli again for his consultation and collaboration in teaching and training grants from the National Institutes of Health. He was always available and very helpful. I soon realized that Dr. Fahey's call and my appointment were through Eli's recommendation and for that I am eternally grateful.
My traineeship in Eli's laboratory prepared me for critical and thoughtful research investigations throughout my academic career. The diverse and intellectual atmosphere reigning in Eli's laboratory was a unique experience, one that I went on to emulate in my own laboratory with my students and fellows. I am indebted to Eli for all he did for me. He was a one-of-a-kind human being with all of the attributes of a compassionate genius.

Eli was my advisor, teacher, consultant, collaborator, and mostly my sincere and true friend whom I loved as family.

Benjamin Bonavida University of California-Los Angeles 